\title{
A Conceptual Framework for Construction and Validation of an Educational Booklet for Treating mothers Misconceptions on vaccination
}

\author{
Samya M. Hegazy ${ }^{1 *}$, Ayat M. Omar ${ }^{1}$, Intisar Alshiekh ${ }^{2}$ \\ ${ }^{1}$ Assistant Professor, Department of Nursing, College of Applied Medical Sciences, Jouf University, Kingdom of Saudi Arabia \\ ${ }^{2}$ Assistant Professor, Department of Nursing, College of Applied Medical Sciences, Jeddah University, Kingdom of Saudi Arabia
}

DOI: $10.36348 /$ sjnhc.2020.v03i02.004 | Received: 05.02.2020 | Accepted: 12.02.2020 | Published: 19.02 .2020

*Corresponding author: Samya M. Hegazy

Abstract

There is no exaggeration to assert that vaccination is one of the greatest scientific discoveries ever made. Generally, mothers' misconception of vaccination was considered as one of the major barriers for better immunization coverage. Previous studies showed misconceptions on mothers' knowledge towards childhood immunization. So, there is a necessity for the mothers to create unequivocal knowledge in order to develop positive attitude towards vaccination and thus improve their contribution to it for reducing the burden of dreadful infectious diseases. Objective: To develop and validate an educational booklet for treating mothers' misconceptions on vaccination. Design: A cross-sectional descriptive study design was adopted in this study for building and validating an educational booklet entitling "Treating mothers' misconceptions on vaccination." The construction of the booklet took place between June to December 2017 at Tanta district health offices through two stages: bibliographic survey; and manufacture of educational materials. Total sample size of 400 mothers of children under five years selected by using convenience sampling technique. Twostructured questionnaires were developed based on relevant literature and adopted throughout the study phases. The first one contained the following data: A) the first part included socio-demographic characteristics of the mothers as age, educational level, occupation, family size and residence. B) The second part included mothers' knowledge towards obligatory vaccination importance, contraindications, and side effects, in addition to all vaccines' mode, time and age of administration. C) The third part included mother's practical knowledge she followed before, during and after vaccinating her child. Moreover, the second questionnaire was used for exploring the mothers and professional experts' opinions in relation to formulation of an educational booklet. Results: The study results indicated that, Out of 400 mothers included in the study, the mean age of the mother whose child undergoing vaccination is $(22.00 \pm 10.68)$ years. The predominant mothers have completed higher education, and occupational status showed that more than two-third $(68.3 \%)$ were house wives. Regarding mothers' knowledge level, The proportion of mothers who lack the knowledge were as follows; vaccination contraindication (86.3\%), Side effects $(60.8 \%)$, BCG (51.5\%), Hepatitis B (87\%), MMR (92.5\%), OPV (54.8\%) and PENTA (94.5\%). Conclusion: It was crucial to construct this booklet to ensure children' mothers' better understanding of the issues surrounding vaccination, treating their misconceptions and for improving their potentials of management of their children' vaccination care.

Keywords: Educational booklet, Childhood vaccination, Children ' mothers, Validation.

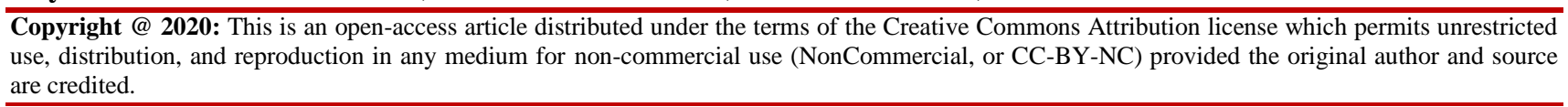

\section{STUDY SIGNIFICANCE}

\section{What is already known about the topic?}

- Vaccination is often cited as one of the most significant contributions of the medical fraternity to mankind. As well as, it is one of the most costeffective child survival interventions which are practiced throughout the world [1]. All countries in the world have a vaccination program to deliver authorized vaccines to the targeted beneficiaries, specially focusing on infants and children, who are at one of the high risk groups for diseases preventable by vaccines. However, this success has always been blocked by mothers' inadequate knowledge, ignorance, and misconceptions.

\section{What this paper adds?}

- This paper provides insight about mothers' general and practical knowledge scores toward their children's obligatory vaccination in Tanta district. In addition to construction, and validation of obligatory vaccination booklet for treating of their misconceptions regarding obligatory vaccination. 


\section{INTRODUCTION}

Childhood vaccination almost guarantees protection from many major diseases. It prevents 2-3 million deaths among children less than 5 years old yearly worldwide [2]. It is not only crucial for the health of children but also for the wider community. To achieve the highest benefit of vaccination, adequate number of population must be vaccinated to cease the spread of the causative microorganisms of the most widespread childhood disease. In addition to develop the highest important phenomenon called 'herd immunity' which is primary and major outcome of massive vaccination activities [3].

The mother plays a major role in promoting the health of children. Several misunderstandings, ignorance and inadequacies of knowledge in relation to obligatory vaccines are prevalent among mothers especially under five children [4]. Mothers' practices for dealing with side effects, negative perceptions in mild illness, negative attitude and mother's misconception about vaccination were considered as some major barrier to childhood vaccination [5]. So, there is a necessity for the mothers to develop unequivocal knowledge and perceptions about vaccinations. As, it helps to reduce the burden of dreadful infectious diseases, which are best controlled by vaccination and so on raise overall vaccination coverage $[6,7]$.

As the vaccinator, the nursing professional has the opportunity to act as an educator at the time of the vaccination, transmitting fundamental information referent to the prevention of illnesses, contributing to the families perceiving the value of immunization, defined as a method capable of avoiding illnesses [8]. In addition to this, in order for the children's mothers to have knowledge about the importance of vaccination, it is necessary for the nursing professional working in the vaccination room to be fully-informed regarding vaccination, as knowledge in the area of health care improves daily practice [9]. Many studies undertaken on the child vaccination situation, however, most of them revealed that there were the shortcomings of knowledge and of communication between the health services and the service users [10].

Globally, national and international health agencies recommend that primary health care should adopt educational strategies and offer children's mothers guidance on a vaccination care, in order to improve satisfaction rate and so on coverage rate [11].
The traditional Vaccine Information Statements (VIS), which providers are required by law to provide to parents (National Childhood Vaccine Injury Act of 1986), have been criticized for their high reading level and for containing insufficient information. Therefore, efforts have been made to evaluate additional informational materials to supplement VIS [12]. The current standard of care is to provide written materials including VIS at each vaccination visit, but fewer paediatricians and family practitioners routinely provide these written materials during immunization visit [13, 14]. In the highlight of what have been mentioned before, the present study was conducted to construct health educational booklet in the field of childhood vaccination to be used as a tool for assuring more knowledge gain, and probably enhance retention.

\section{SUBJECT AND METHODS Study design}

The study design was determined to be crosssectional descriptive study, which was used for surveying the children' mothers' general and practical knowledge regarding obligatory childhood vaccination importance, contraindication, side effects, and its management ...etc. professional experts and mothers' feedback were also explored for completing validation stage of the constructed booklet before developing the final draft.

\section{Setting}

The study conducted at six primary healthcare facilities of Tanta district. These primary facilities were selected according to their population density as it serves large number of children as indicated in table (1).

\section{Subjects and sampling}

The study subjects included two samples to represent the target group of the constructed booklet; the target group was core beneficiaries of the developed booklet who were the mothers of children under five years who came to primary health care centers for vaccinating their children. As well as, pediatric and community experts were the evaluators for the validation stage of the booklet. Convenient sampling technique was used to select the sample involved in both preliminary assessment stage, and evaluation stage of the intended booklet.

\section{Children's mothers}

The actual numbers of children's mothers recruited in the study were (400) mothers who were selected from 6 high population density primary health care facilities as shown in table (1). 
Table-1: Distribution of the recruited mothers from Tanta district primary health care facilities $(\mathrm{N}=400)$

\begin{tabular}{|rl|c|}
\hline \multicolumn{1}{|c|}{ PHC facilities } & Actual sample size \\
\hline 1. & Health office - Tanta 1 & 35 \\
\hline 2. & Health office - Tanta 2 & 25 \\
\hline 3. & Health office - Tanta 3 & 82 \\
\hline 4. & Health office - Tanta 4 & 40 \\
\hline 5. & $\begin{array}{l}\text { Health office - Tanta 5 } \\
\text { (intersection of Botros ) }\end{array}$ & 115 \\
\hline 6. & $\begin{array}{l}\text { Health office - Tanta 6 } \\
\text { (Ciggar village) }\end{array}$ & 103 \\
\hline Total studied mothers sample size & 400 \\
\hline
\end{tabular}

\section{Professional experts and Mothers' feedback post development}

Forty- four mothers and professional academic experts agreed to provide their feedback about the developed booklet; twenty-two for each group. This number of evaluators was sufficient to provide a feedback for content validity of the obligatory childhood vaccination booklet in accordance with the equation for finite populations $\mathrm{n}=\mathrm{Za} 2 . \mathrm{P}(1-\mathrm{P}) / \mathrm{e} 2$. In this equation, $\mathrm{Za}$ (confidence level) was stipulated in $95 \%, \mathrm{P}$ (proportion of experts agreeing with the item) was set at $85 \%$ and "e" (expected difference) was $15 \%$, so that the calculated sample was 22 participants for each group [15].

\section{Process of booklet construction and validation}

Among the various approaches for constructing health educational materials, this study used Echer's methodology [16], which clarifies the approach of developing teaching materials for health care. Several studies related to the construction of educational materials followed these assumptions [17, 18]. For this study, we adopted the following stages: bibliographic survey and preparation of educational materials.

\section{Bibliographic survey stage}

The Preliminary survey was concerned about assessing children' mothers' general and practical knowledge regarding obligatory vaccination. During this stage, it was important to figure out opinions of professional experts in relation to the structure, and content of the intended booklet.

\section{DATA COLLECTION TOOLS}

Two tools were included in conducting the preliminary assessment. The first tool composed of three parts A) "Self-administrated Socio-demographic characteristics part." This part was used to assess socio-demographic characteristics of children's mothers such as age, sex, education, occupation, and family size. The second part was "Self-administered general knowledge assessment part" that was designed to test mothers' general knowledge with 38 knowledge items, which required true, or false answers relating to diseases controlled by obligatory vaccination, importance, contraindication, and vaccination schedule with routes and doses. C) "Self-administered practical knowledge assessment part" that was developed to test mothers' practical knowledge with 18 knowledge items regarding management of vaccination care. Correct answer scored $=(1)$, while an incorrect answer scored $=$ (0). The total knowledge score was categorized into three levels as stated by Ramadan et al. [19]. The knowledge scores categories were a poor score $=$ less than $50 \%$ of the total score, a fair score $=50$ to $65 \%$ of the total score, and a good score $=$ more than $65 \%$ of the total score. The second tool was "Structured selfadministered feedback questionnaire of Children's mothers and professional experts about criteria of the constructed booklet." This questionnaire was used to explore the Children's mothers and professional experts' opinions concerning structure and content of the constructed booklet.

\section{Reliability of the questionnaires}

Internal consistency reliability (Cronbach's $\alpha$ ) for the first questionnaire emerged as high (0.7580.922).For and each domain, A) socio-demographic part (Cronbach's $\alpha=0.758)$, B) general knowledge part (Cronbach's $\alpha=0.922$ ) and, C) practical knowledge part (Cronbach's $\alpha=0.831)$.

For the second questionnaire: emerged as high (0.719-0.725). For and each domain, A) expert ' feedback part (Cronbach's $\alpha=0.725$ ), and B) nurses ' feedback part (Cronbach's $\alpha=0.719$ ).

\section{Preparation of the health educational booklet}

According to Reberte et al. [20], the preparation stage of the intended booklet composed of six steps as shown in (Figure 1), carried out in the period from June to December 2017. 


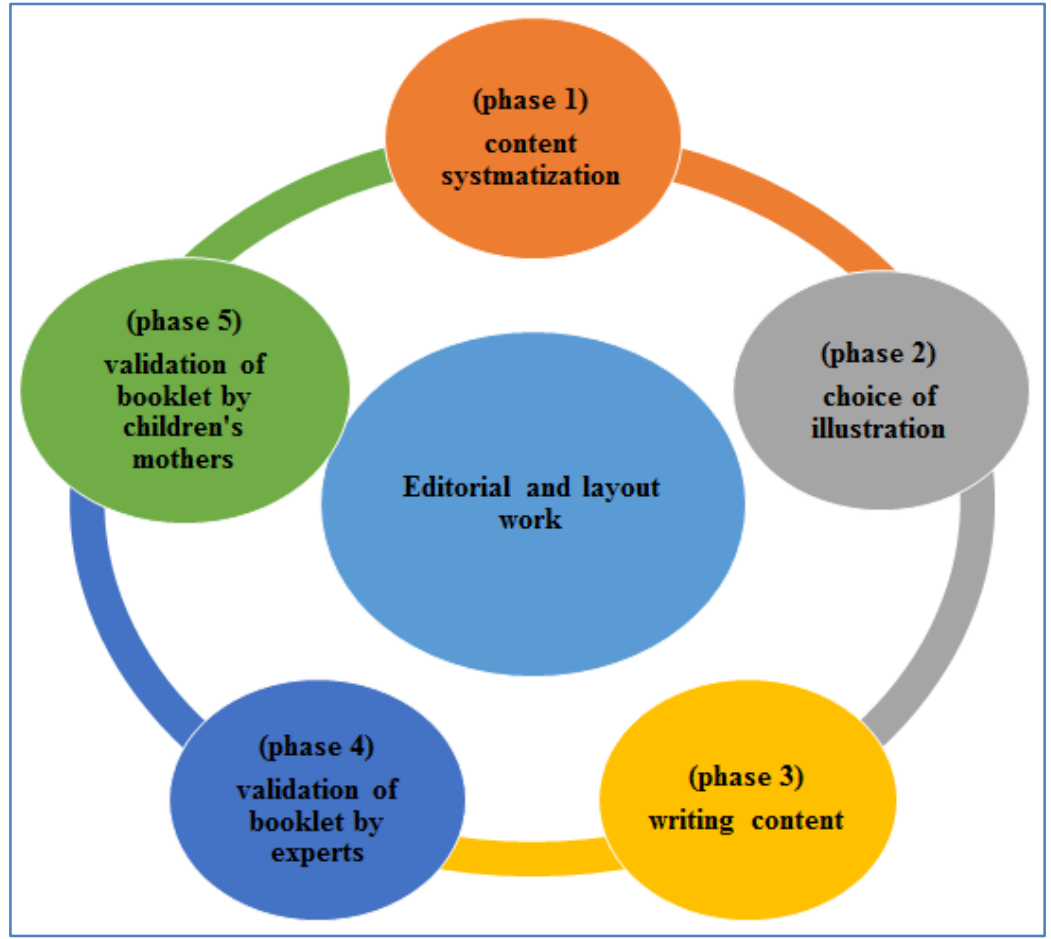

Fig-1: The preparation stage of the health educational booklet

\section{Development phase of the health educational booklet}

- According to the primary situational analysis results, which indicated lack of adequate general and practical knowledge of children's mothers, in addition to the reviewed literatures, this educational booklet were developed.

- The intended protocol was appraised for its content validity by obtaining experts and children's mothers' feedback. The feedback was obtained by the second tool, which concerned with the booklet structure, content, and its illustrations form. The initial draft of the constructed booklet was disseminated to 22 experts and 22 children's mothers to test content validity of the booklet. Any specific comments and recommended modifications from experts' evaluation were documented and considered in the formulation process of the final booklet draft.

\section{Official, ethical and other technical issues}

- Ethical approval was obtained from the research ethics committee that affiliated to the Faculty of Nursing- Tanta University. Oral consents were obtained from children's mothers to participate in the study after illustrating the purpose of it. The collected data is considered confidential and kept in a closed cabinet for 5 years and reached only by the research team only $[11,22]$.

- An official approval from the dean of Faculty of Nursing- Tanta University and the vice dean for higher graduate studies was submitted to MOHP Directorate to obtain approval for conducting the study at the selected primary healthcare facilities.
- The content validity of the developed tools was tested by five experts of pediatric nursing. In addition to, a pilot study that was conducted on 10 $\%$ of mothers (40 mothers) who were selected randomly from different Tanta district health offices and were not included from the studied sample. The pilot study aimed to evaluate the clarity and applicability of the research tools in addition to, estimation the approximate time required for data collection. Accordingly, the necessary modification was done, some questions were added, and others were clarified or omitted.

\section{STATISTICAL ANALYSIS}

Statistics in the form of simple frequency tables for nominal and categorical variables and arithmetic mean \pm standard deviation for continuous variables were calculated after analyzing data by SPSS (Stand for Statistical Productive and Service Solution) version 20 .

\section{RESULT}

Results divided into three parts; firstly, the results of pre-booklet construction (needs assessment). Secondly, description of the constructed content, and finally, the booklet content validation.

\section{Preliminary assessment}

Table (2) indicates that $67.2 \%$ of respondents were between $18->28$ years with mean age of $22.00 \pm$ 10.68 years old. Concerning educational level, $39.2 \%$ of them have bachelor degree. Regarding marital status, $83.5 \%$ of them were married and live in rural areas. As regarding their occupation, $68.3 \%$ of them were house 
wives. As shown in the figure (2), nearly the highest percent of respondents acquire their vaccination knowledge from PHC facility and preferred the booklet as the most convenient health educational material. The table also reveals husband characteristics. For husband education, $26.5 \%$ of husbands were only primary level. Finally, regarding husband occupation, $35.8 \%$ of them were the clerks.

Table-2: Distribution of the studied mothers according to their socio-demographic characteristics $(\mathrm{N}=400)$

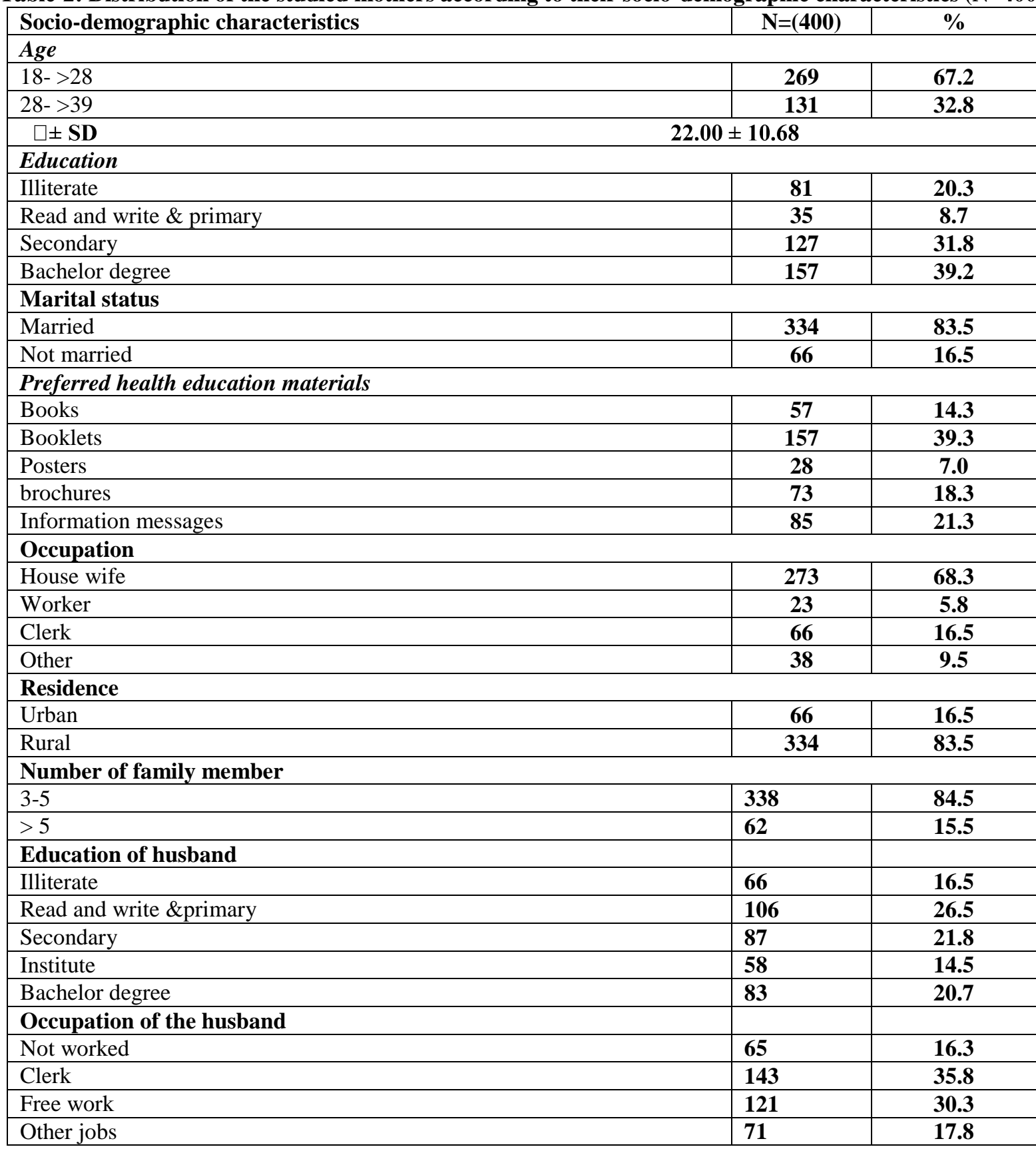




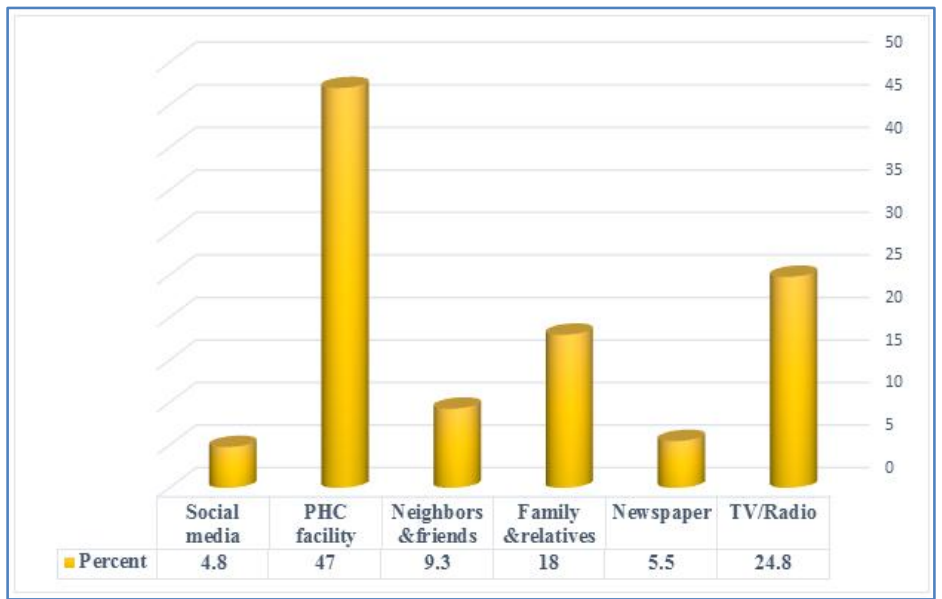

Fig-2: Mothers' vaccination knowledge sources

\section{*Multiple responses}

Table (3) reveals that more than half of the respondents could not identify number of doses, mode, and age of BCG and OPV administration. As well as, less than one-sixth of them choose number of doses, mode, and disease controlled by vaccine and age of administration in relation to MMR, Hepatitis B, PENTA vaccines correctly.

Table-3: Distribution of the studied mothers according to their knowledge about childhood vaccines

\begin{tabular}{|c|c|c|}
\hline Items & $N=(400)$ & $\%$ \\
\hline \multicolumn{3}{|l|}{ BCG vaccine } \\
\hline Disease controlled by the vaccine & 202 & 50.5 \\
\hline Number of doses & 194 & 48.5 \\
\hline Mode of administration & 186 & 46.5 \\
\hline Age of child at administration & 194 & 48.5 \\
\hline \multicolumn{3}{|l|}{ OPV vaccine } \\
\hline Disease controlled by the vaccine & 181 & 45.3 \\
\hline Number of doses & 166 & 41.5 \\
\hline Mode of administration & 219 & 54.8 \\
\hline Age of child at administration & 181 & 45.3 \\
\hline \multicolumn{3}{|l|}{ Hepatitis B vaccine } \\
\hline Disease controlled by the vaccine & 47 & 11.8 \\
\hline Number of doses & 52 & 13 \\
\hline Mode of administration & 41 & 10.3 \\
\hline Age of child at administration & 52 & 13 \\
\hline \multicolumn{3}{|l|}{ MMR vaccine } \\
\hline Disease controlled by the vaccine & 36 & 9 \\
\hline Number of doses & 30 & 7.5 \\
\hline Mode of administration & 22 & 5.5 \\
\hline Age of child at administration & 30 & 7.5 \\
\hline \multicolumn{3}{|l|}{ PENTA vaccine } \\
\hline Disease controlled by the vaccine & 28 & 7 \\
\hline Number of doses & 22 & 5.5 \\
\hline Mode of administration & 22 & 5.5 \\
\hline Age of child at administration & 22 & 5.5 \\
\hline
\end{tabular}

Table (4) shows less than three-fourth $(70.3 \%)$ of the respondents stated importance of vaccination as protection from infectious diseases, improvement of immune system and enjoying good health. Concerning side effects of vaccination, the respondents correct responses as the follow; $84.8 \%$ for " Pain at site of injection," $71.3 \%$ for " Redness and swelling," $62.5 \%$ for" Fever up to 39," and $42 \%$ for " Appearance of bullae at the site of BCG injection." As regarding to vaccination contraindication, less than one-sixth of 
them choose Allergy to vaccine, diarrheal disease, family history of immunosuppressive disorders and AIDS as true vaccination contraindications, as well as, $64.8 \%$ of respondents stated chemotherapy and radiotherapy as major barriers for vaccinating their children. In accordance with total mother' general knowledge, $83.8 \%$ of them showed poor score of knowledge with mean $11.93 \pm 8.18$ points as shown in Figure (3).

Table-4: Distribution of the studied mothers according to their knowledge about childhood vaccination importance, contraindication and its side effects

\begin{tabular}{|c|c|c|}
\hline Items & $\mathrm{N}=(400)$ & $\%$ \\
\hline \multicolumn{3}{|l|}{ Importance of vaccination* } \\
\hline Protection from infectious diseases & 241 & 60.3 \\
\hline Improvement of immune system & 235 & 58.8 \\
\hline Enjoying good health & 281 & $\mathbf{7 0 . 3}$ \\
\hline All of above & 281 & $\mathbf{7 0 . 3}$ \\
\hline \multicolumn{3}{|l|}{ Side effects of vaccination } \\
\hline Pain at site of injection & 339 & 84.8 \\
\hline Redness and swelling & 285 & 71.3 \\
\hline Fever up to39 & 250 & 62.5 \\
\hline Appearance of bullae at the site of BCG injection & 168 & 42 \\
\hline Paralytic poliomyelitis & 53 & 13.3 \\
\hline Convulsions & 34 & 8.5 \\
\hline Rash & 61 & 15.3 \\
\hline \multicolumn{3}{|l|}{ Contraindications of vaccination } \\
\hline Allergy to vaccine & 63 & 15.8 \\
\hline Allergy to vaccine components & 58 & 14.5 \\
\hline Treatment with immune-suppressive drugs & 59 & 14.8 \\
\hline Chemotherapy and radiotherapy & 259 & 64.8 \\
\hline Moderate and severe diarrheal disease & 55 & 13.8 \\
\hline Family history of immunosuppressive disorders & 69 & 17.3 \\
\hline AIDS children & 55 & 13.8 \\
\hline
\end{tabular}

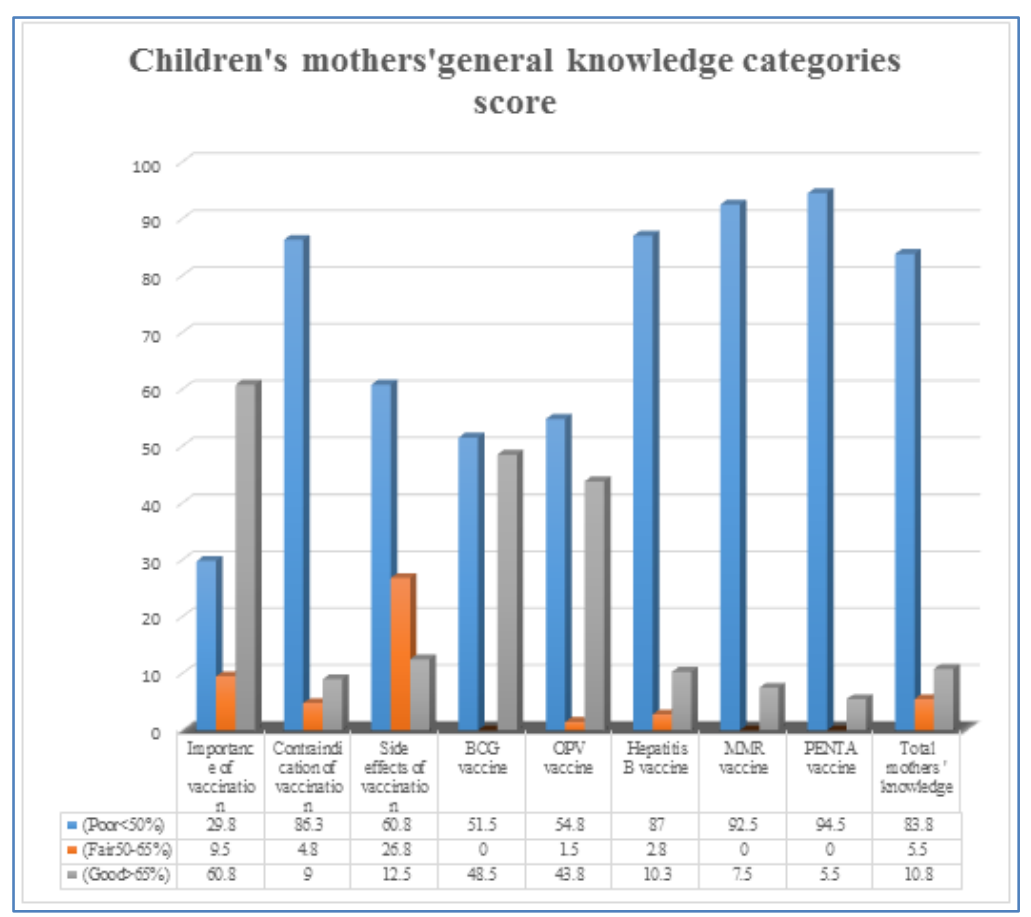

Fig-3: Children's mothers'general knowledge categories score 
Table (5) illustrates that most of the respondents (94.3\%) were bringing their child's vaccination card. As well as, three-fourth of them was dressing their children suitable clothes for vaccine administration. In relation to child's attention distraction, half of the respondents talk to their children and using toys as methods of distraction. Concerning mothers' practical knowledge after vaccination, less than half of respondents $(44 \%)$ has satisfactory knowledge regarding management of post vaccination swelling. As regarding for post vaccination fever, more than half of respondents $(54.5 \%)$ demonstrated appropriate management of post vaccination fever. In accordance with total mothers' practical knowledge, two-third of respondents showed poor level of practical knowledge with $7.33 \pm 2.85$ points as shown in figure(4).

Table-5: Distribution of the studied mothers according to their practical knowledge before, during and after vaccinating their children

\begin{tabular}{|c|c|c|}
\hline Item & $\mathrm{N}=(\mathbf{4 0 0})$ & $\%$ \\
\hline \multicolumn{3}{|l|}{ Mothers' practical knowledge before vaccinating their children: } \\
\hline Bring child's vaccination card & 377 & 94.3 \\
\hline In case of sickness, the child 'mother should bring all the prescribed medication & 157 & 39.3 \\
\hline Report the previous vaccinations side effects & 99 & 24.8 \\
\hline Dressing your child suitable clothes for vaccine administration & 299 & $\mathbf{7 4 . 8}$ \\
\hline \multicolumn{3}{|l|}{ Distracting child ' attention by: } \\
\hline Talking to him/her & 220 & 55 \\
\hline Using toys & 162 & 40.5 \\
\hline Giving two drops of glucose solution & 60 & 15 \\
\hline \multicolumn{3}{|l|}{ Mothers' practical knowledge during vaccinating their children: } \\
\hline Cuddle your child during vaccination & 299 & $\mathbf{7 4 . 8}$ \\
\hline Distracting child ' attention during vaccination by the previous measures & 63 & 15.8 \\
\hline \multicolumn{3}{|l|}{ Mothers' practical knowledge after vaccinating their children: } \\
\hline lactate your child after vaccine administration & 127 & 31.8 \\
\hline \multicolumn{3}{|l|}{ Appropriate management of swelling } \\
\hline Cold compress & 176 & 44 \\
\hline Starch & 69 & $\mathbf{1 7 . 3}$ \\
\hline Analgesic and local anti-inflammatory & 100 & 25 \\
\hline \multicolumn{3}{|l|}{ Appropriate management of fever } \\
\hline Inform your doctor in case fever up to 39 & 33 & 8.3 \\
\hline Give the prescribed antipyretic (parastmole) & 217 & 54.3 \\
\hline Avoid giving acetylsalicylic acid (aspirin or aspocid) & $\mathbf{8 0}$ & 20 \\
\hline Apply cold compresses at the site of administration & 218 & 54.5 \\
\hline Dress child light clothes & 178 & 44.5 \\
\hline
\end{tabular}

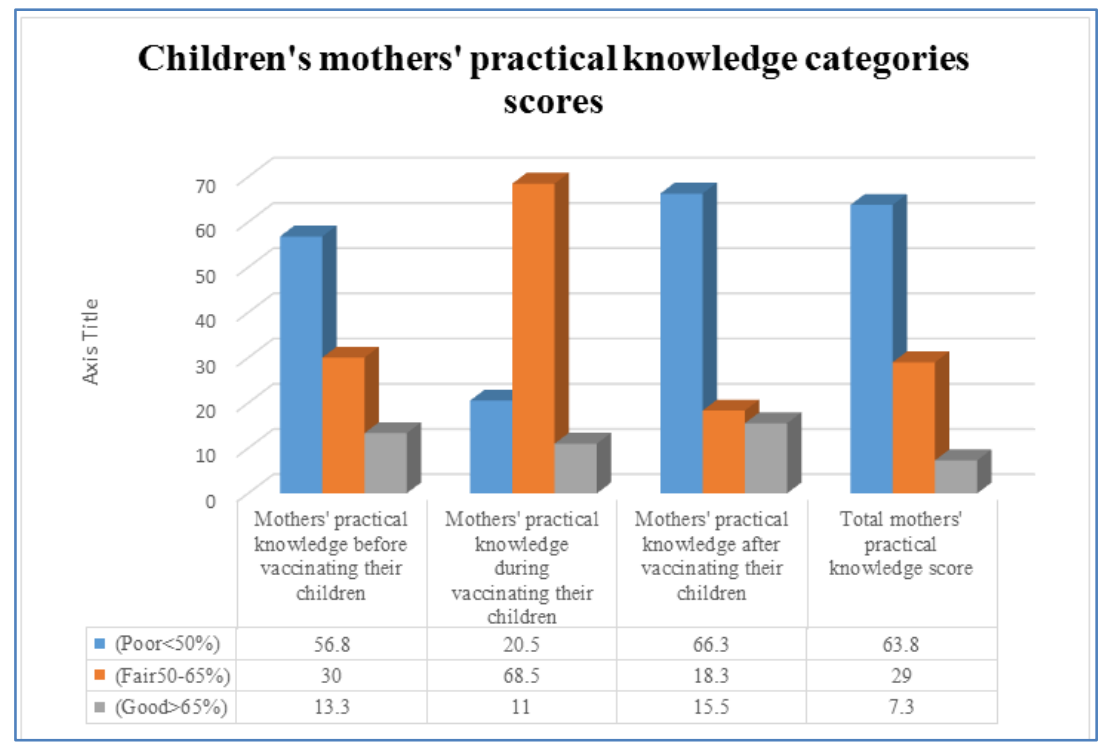

Fig-4: Children's practical knowledge categories score 


\begin{tabular}{|c|l|}
\multicolumn{2}{|l}{ Box (1): Description of the constructed health education booklet } \\
\hline Language & Arabic version \\
\hline $\begin{array}{c}\text { Introduction } \\
\text { Content }\end{array}$ & $\begin{array}{l}\text { Highlight on: } \\
\text { Importance of obligatory childhood vaccination for under five children }\end{array}$ \\
\hline $\begin{array}{c}\text { Importance of vaccination for } \\
\text { children }\end{array}$ & $\begin{array}{l}\text { This section describes the benefits of vaccination for under five children which are protection from } \\
\text { the most virulent childhood infectious disease. }\end{array}$ \\
\hline $\begin{array}{c}\text { Side effects of vaccination } \\
\text { Schedule of obligatory } \\
\text { vaccination }\end{array}$ & $\begin{array}{l}\text { This section provides instructions on vaccination side effects and how to manage these post- } \\
\text { vaccination reactions. }\end{array}$ \\
\hline $\begin{array}{c}\text { Diseases that controlled by } \\
\text { vaccination }\end{array}$ & $\begin{array}{l}\text { This section illustrates information about name of each vaccine dose, time and rout of } \\
\text { administration. }\end{array}$ \\
\hline $\begin{array}{c}\text { True and false vaccination } \\
\text { contraindications }\end{array}$ & $\begin{array}{l}\text { This section provides illustrations about real and pseudo contraindications for childhood } \\
\text { vaccination for correcting any misunderstanding about it. }\end{array}$ \\
\hline $\begin{array}{c}\text { Role of mother before } \\
\text { vaccination }\end{array}$ & $\begin{array}{l}\text { This section demonstrates the mother' role before vaccinating their children; what she should take } \\
\text { in her considerations and do before going for vaccination. }\end{array}$ \\
\hline $\begin{array}{c}\text { Role of mother during } \\
\text { vaccination }\end{array}$ & $\begin{array}{l}\text { This section demonstrates the mother' role during vaccinating their children; what she should } \\
\text { perform during vaccination session. }\end{array}$ \\
\hline $\begin{array}{c}\text { Role of mother after } \\
\text { vaccination }\end{array}$ & $\begin{array}{l}\text { This section demonstrates the mother' role after vaccinating their children; how she can manage } \\
\text { post vaccination side effects. }\end{array}$ \\
\hline
\end{tabular}

\section{Evaluation of content validity}

Table (6) reveals that most experts and mothers $(95.5 \%)$ mentioned that the topic of the constructed booklet is significant for the target population. Regarding the booklet's objectives, (95.5\%) of experts and mothers agreed on the objectives are specific, achievable, measurable, and reliable and time bounded. In relation to the content, $81.8 \%$ of experts and $90.9 \%$ of mothers stated that the booklet content is sufficient to achieve the objectives and matched to the native culture. Furthermore, majority of experts and most of the mothers mentioned that the material vocabulary is composed of popular words, and sequence of information is consistent, making it easier for the readers to predict its flow. Most of the experts and all mothers mentioned that the booklet legibility and printing characteristics are suitable. Moreover, the used media are obvious and grasp attention. In conclusion, total experts' and nurses evaluation regarding the developed booklet material is good.

Table-6: Distribution of professional experts' and children' mothers according to their feedback about the constructed booklet $(\mathrm{N}=22)$

\begin{tabular}{|c|c|c|c|c|}
\hline \multirow[t]{2}{*}{ Evaluation items } & \multicolumn{2}{|c|}{$\begin{array}{c}\text { children' mothers' feedback } \\
\mathrm{N}=(\mathbf{2 2})\end{array}$} & \multicolumn{2}{|c|}{$\begin{array}{l}\text { Experts' feedback } \\
\qquad \mathrm{N}=(\mathbf{2 2})\end{array}$} \\
\hline & $\mathbf{N}$ & $\%$ & $\mathbf{N}$ & $\%$ \\
\hline \multicolumn{5}{|l|}{ Topic } \\
\hline The topic of educational booklet is significant & 21 & 95.5 & 21 & 95.5 \\
\hline \multicolumn{5}{|l|}{ Objectives and contents } \\
\hline The objectives are SMART & 21 & 95.5 & 21 & 95.5 \\
\hline Content is sufficient to achieve the objectives. & 20 & 90.9 & 18 & 81.8 \\
\hline Content is updated & 20 & 90.9 & 16 & 72.7 \\
\hline Content is matched to the native culture & 19 & 86.4 & 18 & 81.8 \\
\hline Content is concise & 18 & 81.8 & 21 & 95.5 \\
\hline \multicolumn{5}{|l|}{ Literary Presentation } \\
\hline Majority of the vocabulary is composed of popular words & 20 & 90.9 & 19 & 86.4 \\
\hline $\begin{array}{l}\text { Planning and sequence of information are consistent, making it } \\
\text { easier for the readers to predict its flow. }\end{array}$ & 21 & 95.5 & 18 & 81.8 \\
\hline \multicolumn{5}{|l|}{ Legibility and printing characteristics } \\
\hline Size and style of the letters are suitable & 22 & 100 & 20 & 90.9 \\
\hline The space between lines and paragraphs are suitable. & 22 & 100 & 20 & 90.9 \\
\hline Length of the paragraphs is proper & 20 & 90.9 & 21 & 95.5 \\
\hline $\begin{array}{l}\text { Use of bold characters and bullet points draw attention to specific } \\
\text { points or key content }\end{array}$ & 21 & 95.5 & 20 & 90.9 \\
\hline \multicolumn{5}{|l|}{ The used media } \\
\hline The media is appropriate to the content delivered & 22 & 100 & 20 & 90.9 \\
\hline The used media is grasping attention & 22 & 100 & 21 & 95.5 \\
\hline The used media is obvious & 22 & 100 & 21 & 95.5 \\
\hline $\begin{array}{l}\text { Total evaluation score } \\
\qquad \quad \text { Good }\end{array}$ & 21 & 94.2 & 20 & 89.4 \\
\hline
\end{tabular}




\section{DISCUSSION}

Educational materials play an important role in the process of health education, as they not only facilitate the mediation of the learning content, but also function as a resource readily available so that clients and their families can refer to it when faced with uncertainty in the development of care. It is noteworthy that the increasing use of educational materials as resources in health education has assumed an important role in the teaching-learning process, especially in the care management of major public concerns [23]. Therefore, the current study aimed at constructing an educational booklet about vaccination for correcting mothers' misunderstanding about it. Prior to the development of this booklet, it was important to explore children mothers' general and practical knowledge regarding the obligatory vaccination.

In accordance with Socio-demographic characteristics of the studied mothers which consisted of 400 mothers ranged from 18- >28 years, with Mean \pm SD $22.00 \pm 10.68$ years. The present study referred that nearly two-third of the mothers had Bachelor degree, majority of them were married and house wives. These findings are in the same line with interpretations of many conducted studies of that were implemented in Egypt, Nigeria, India, Saudi Arabia and Enugu [24, 25, $26,27]$. These studies revealed the same findings of the present study in relation to Scio-demographic characteristics as age, marital status, and occupation and qualification level. Also concerning mean age of the studied mothers, it was 22 years old which is similar to Mugada et al. [38] study who revealed that the mean age of his studied sample was 22 years old. As regarding to the studied mothers' occupation and marital status, the present study revealed that the large percent of them $(68.3 \%)$ were house wife and $(83.5 \%)$ of them were married which is consistent with Ramadan et al. [19].

In relation to mothers' vaccination source of information, this study concluded that the large percent of mother gain their vaccination information from PHC clinics which is observed in a study carried out in Oyo state by Adeyinka [29] who reported the most common source of information was also at the antenatal clinics $(65.7 \%)$. This is, however, disagreeing with studies carried out in Karachi Pakistan, North India, Saudi Arabia and Bangladesh where $62.2 \%, 52.0 \%, 88 \%$, $77 \%$, and $80.18 \%$ of the respondents, respectively stated that the commonest source of information about the immunization of under-five children was through health workers at other hospital visits other than antenatal clinics [30-33].

To construct the intended health educational booklet throughout the present study, it was necessitated to survey mothers' general and practical knowledge regarding all sides of childhood vaccination before building the last version of the intended booklet.
Concerning the total mothers' general knowledge level, the current study indicated that $(83.8 \%)$ of mothers showed poor general knowledge score. This interpretation may be due to insufficiency of educational interventions (training programs, seminars, conferences, and workshops) that are directed for raising mothers' awareness about their children vaccination. The findings of the current study were similar to many conducted studies; the first one was conducted by [34], in Saudi Arabia, who reported that mothers' knowledge about EPI vaccination was quite low. As well as, similar studies done in Pakistan and India, have also reported that the same finding in relation to the level of knowledge [30, 1, 34]. On the opposite side, there are many studies contradict this finding, as those implemented by $[36,37,38,39]$ who reported that good knowledge, positive attitude and good practice of the mothers towards childhood immunizations.

The mothers' efficient practice is essential contributing factor for success of national childhood vaccination programs. Therefore, it was crucial to evaluate mothers' practical knowledge. The present study indicated that deficiency of practical knowledge among the studied sample, which is alarming for rapid corrective intervention. In the same respect, many studies report the same results, lack of adequate practical knowledge [40]. In the other line, it is incompatible with many studies all over the world. The first one was developed by Siddiqui et al. [41] in India, which concluded $57.97 \%$ of the study population was found to have adequate knowledge-practice scores. Moreover, other studies were conducted by [42, 27, 37, 38,39 ] who reported that the practice of majority of the studied mothers towards vaccination is satisfactory.

Educational interventions designed for mothers can have significant participation for raising vaccination uptake. Educating low-literate mothers by using pictorial messages and very simple language improved the completion vaccine uptake by $39 \%$ [43]. Based on this implication, the researcher constructed the intended health educational booklet for correcting mothers' misconceptions about vaccination. The developed booklet was validated by professional experts and mothers of children less than five years who mentioned that all information was accurate, the content is sufficient to achieve the objectives, appropriate to the level of understanding, updated, concise, and written in a mothers' oriented style. This finding is observed in the study conducted by Friedman [9] who reported the same evaluation. More ever, there are three other congruent studies conducted in different world regions. As in Germany, a study has showed that using balanced health information leaflets can increase girls' and parents' knowledge of the human papillomavirus vaccination and vaccination uptake [44]. As well as, Gross et al. [45] reported that an increase in college females' intent to vaccinate by nearly threefold after 
displaying a 20-minute educational presentation about human papillomavirus vaccination. Lastly, the third study of Barrera et al. [46] indicated that parents in Guatemala repeatedly revealed that workshops at the community level is the best way to increase their awareness and knowledge of vaccinations.

\section{CONCLUSION}

It was crucial to construct this booklet to ensure children' mothers' better understanding of the issues surrounding vaccination, treating their misconceptions and for improving their potentials of management of their children' vaccination care.

\section{RECOMMENDATIONS}

- Comparable studies can be conducted on large sample for a longer period of time to be generalized on total population.

- Comparable studies can be conducted in different settings.

- Other special educational interventions should be implemented on large scale for raising mothers' awareness on vaccination.

\section{REFERENCES}

1. Angadi, M. M., Jose, A. P., Udgiri, R., Masali, K. A., \& Sorganvi, V. (2013). A study of knowledge, attitude and practices on immunization of children in urban slums of Bijapur city, Karnataka, India. Journal of clinical and diagnostic research: JCDR, 7(12), 2803.

2. UNICIF. (2015). Immunization Facts and Figures Nov 2015 Update. Retrieved from: https://www.unicef.org/immunization/files/Immun ization_Facts_and_Figures_Nov_2015_update.pdf

3. Australian Government Department of Health. (2014). Vaccination. Retrieved from: http://www.immunise.health.gov.au/internet/immu nise/publishing.nsf/Content/introduction-ai

4. Akmatov, M. K., Kretzschmar, M., Krämer, A., \& Mikolajczyk, R. T. (2007). Determinants of childhood vaccination coverage in Kazakhstan in a period of societal change: implications for vaccination policies. Vaccine, 25(10), 1756-1763.

5. Al-Lela, O. Q. B., Bahari, M. B., Al-Qazaz, H. K., Salih, M. R., Jamshed, S. Q., \& Elkalmi, R. M. (2014). Are parents' knowledge and practice regarding immunization related to pediatrics' immunization compliance? a mixed method study. BMC pediatrics, 14(1), 20.

6. Gellin, B. G., Maibach, E. W., \& Marcuse, E. K. (2000). Do parents understand immunizations? A national telephone survey. Pediatrics, 106(5), 1097-1102.

7. Ivey, R. A., Subramanian, C., \& Bruce, B. D. (2000). Identification of a Hsp70 recognition domain within the rubisco small subunit transit peptide. Plant Physiology, 122(4), 1289-1300.
8. Santos, L. B., Barreto, C. C. M., Silva, F. L. S., \& Silva, K. C. D. O. (2011). Percepção das mães quanto à importância da imunização infantil.

9. Feitosa, L. R., Feitosa, J. A., \& de Lavor Coriolano, M. W. (2010). Conhecimentos e práticas do auxiliar de enfermagem em sala de imunização. Cogitare Enfermagem, 15(4), $695-$ 701.

10. Molina, A. C., de Godoy, I., De Carvalho, L. R., \& Júnior, A. L. C. (2007). Situação vacinal infantil e características individuais e familiares do interior de São Paulo. Acta Scientiarum. Health Sciences, 29(2), 99-106.

11. Ministério da Saúde, Cadernos de Atenção, Básica. (2012). Atenção ao Pré-Natal de Baixo Risco. Brasília: Ministério da Saúde;

12. Klein, N. P., Kissner, J., Aguirre, A., Sparks, R., Campbell, S., Edwards, K. M., ... \& Gust, D. A. (2009). Differential maternal responses to a newly developed vaccine information pamphlet. Vaccine, 28(2), 323-328.

13. Davis, T. C., Fredrickson, D. D., Arnold, C. L., Cross, J. T., Humiston, S. G., Green, K. W., \& Bocchini, J. A. (2001). Childhood vaccine risk/benefit communication in private practice office settings: a national survey. Pediatrics, 107(2), e17-e17.

14. Shui, I., Kennedy, A., Wooten, K., Schwartz, B., \& Gust, D. (2005). Factors influencing AfricanAmerican mothers' concerns about immunization safety: a summary of focus group findings. Journal of the National Medical Association, 97(5), 657.

15. De Oliveira Lopes, M. V., da Silva, V. M., \& de Araujo, T. L. (2012). Methods for establishing the accuracy of clinical indicators in predicting nursing diagnoses. International Journal of Nursing Knowledge, 23(3), 134-139.

16. Echer, I. C. (2005). Elaboração de manuais de orientação para o cuidado em saúde. Revista Latino-Americana de Enfermagem, 13(5), 754757.

17. Barros, L. M. (2015). Construção e validação de uma cartilha educativa sobre os cuidados no perioperatório da cirurgia bariátrica.

18. Costa, P. B., Chagas, A. C. M. A., Joventino, E. S., Dodt, R. C. M., Oriá, M. O. B., \& Ximenes, L. B. (2013). Construção e validação de manual educativo para a promoção do aleitamento materno. Revista da Rede de Enfermagem do Nordeste, 14(6), 1160-1167.

19. Ramadan, H. A., Soliman, S. M., \& El-kader, R. G. A. (2016). Knowledge, attitude and practice of mothers toward children's obligatory vaccination. Journal of Nursing and Health Science, 5(4), 22-28.

20. Reberte, L. M., Hoga, L. A. K., \& Gomes, A. L. Z. (2012). Process of construction of an educational booklet for health promotion of pregnant 
women. Revista Latino-Americana de Enfermagem, 20(1), 101-108.

21. World Medical Association, WMA. (2011). Declaration of Helsinki: Ethical principles for medical research involving human subjects. Geneva, WMA. Retrieved from: http://www.wma.net/en/30publications/10policies/ b3/index.html.

22. Etene. (2009). Muistilista eettisten toimikuntien jäsenille ja tutkijoille. Retrieved from: http://www.tukija.fi/c/document_library/get_file?f olderId=18753\&name=DLFE-680.pdf

23. Coriolano-Marinus, M., Pavan, M., Lima, L., \& Bettencourt, A. (2014). Validation of educational material for hospital discharge of patients with prolonged domiciliary oxygen prescription. Escola Anna Nery - Revista De Enfermagem, 18(2). Retrieved from: http://www.scielo.br/scielo.php?pid=S1414$81452014000200284 \&$ script=sci_arttext\&tlng=en

24. Chris-Otubor, G. O., Dangiwa, D. A., Ior, L. D., \& Anukam, N. C. (2015). Assessment of knowledge, attitudes and practices of mothers in Jos North regarding immunization. IOSR Journal of Pharmacy, 5(6), 34-45.

25. Savadi, V., Sumitra, 1. A., hulgibali, M. (2017). A Study To Assess The Knowledge Regarding Immunization Among The Mothers Of Fewer than Five Children Admitted In Pediatric Ward Of Prabhakar Kore Hospital, Belagavi With The Aim To Develop Educational Pamphlet". IOSR Journal of Nursing and Health Science, 6(6), 68-73 Retrieved from: www.iosrjournals.org.

26. Alenazi, A. A. S., Alshareef, R. A., Alabudib, F. A., \& Almuqarrab, A. J. H. (2017). Assessment of knowledge and attitude and practice of parents about immunization in Jeddah City, 2017. The Egyptian Journal of Hospital Medicine, 69(7), 2939-2943.

27. Tagbo, B. N., Uleanya, N. D., Nwokoye, I. C., Eze, J. C., \& Omotowo, I. B. (2012). Mothers' knowledge, perception and practice of childhood immunization in Enugu. Nigerian Journal of paediatrics, 39(3), 90-96.

28. Mugada, V., Chandrabhotla, S., Kaja, D. S., \& Machara, S. G. K. (2017). Knowledge towards childhood immunization among mothers \& reasons for incomplete immunization. Journal of Applied Pharmaceutical Science, 7(10), 157-161.

29. Adeyinka, D. A., Oladimeji, O., Adeyinka, F. E., \& Aimakhu, C. (2009). Uptake of childhood immunization among mothers of under-five in Southwestern Nigeria. The internet journal of epidemiology, 7(2), 1-15.

30. Nisar, N., Mirza, M., \& Qadri, M. H. (2010). Knowledge, Attitude and Practices of mothers regarding immunization of one year old child at Mawatch Goth, Kemari Town, Karachi. Pak J Med Sci, 26(1), 183-186.
31. Nath, B., Singh, J. V., Awasthi, S., Bhushan, V., Kumar, V., \& Singh, S. K. (2008). KAP study on immunization of children in a city of North Indiaa 30 cluster survey. Online Journal Of Health and Allied Sciences, 7(1).

32. Al-Zahrani, J. (2013). Knowledge, attitude and practice of parents towards childhood vaccination. Majmaah Journal of Health Sciences, 216(1216), 1-20.

33. Salam, M. M., Uddin, M. S., Khan, M. F. A., Mazumdar, P. K., Huq, M. E., Yousuf, R., \& Salam, A. (2013). Maternal awareness on under-5 child immunization in a rural community of Bangladesh. Int Med J, 20(6), 681-684.

34. Gul, S., \& Khalil, R. (2016). Immunisation knowledge and practices among mothers attending a paediatric clinic in Karachi, Pakistan. International Journal of Advances in Medicine, 3(3), 656-61.

35. Aslami, A. N., Athira, T. K., Salim, A. K., Pillai, A. V., Asha, T. J., \& Bency, S. (2015). Assessment of Knowledge about Immunization of Under Five Children among Mothers Attending Outpatient Department of Pediatrics in a Tertiary Care Hospital in Kollam, Kerala". Journal of Evidence based Medicine and Healthcare, 2(29), 4191-200.

36. Hamid, S., Andrabi, S. A. H., Fazli, A., \& Jabeen, R. (2012). Immunization of Children in a Rural Area of North Kashmir, India: A KAP Study. Online Journal of Health and Allied Sciences, 11(1 (10).

37. Bernsen, R. M., Al-Zahmi, F. R., Al-Ali, N. A., Hamoudi, R. O., Ali, N. A., Schneider, J., ... \& Grivna, M. (2011). Knowledge, attitude and practice towards immunizations among mothers in a traditional city in the United Arab Emirates. $J$ Med Sci, 4(3), 114-121.

38. Abidoye, A. O., \& Odeyemi, K. A. (2013). Knowledge, attitude and practice of mothers to childhood immunization in Kosofe Local Government Area of Lagos State, Nigeria. International Journal of Basic, Applied and Innovative Research, 2(4), 66-72.

39. Agboola, S. M., Busari, O. A., Segun-Agboola, B. T., Olajide, T. J., Shabi, O. M., \& Elegbede, O. T. (2015). Knowledge, attitude, perceptions of adult males towards childhood immunizations in southwest Nigeria. American Journal of Health Research, 3(1), 1-5.

40. Shoma, F. N., Shah, N. A., Sarker, M. N., Islam, M. S. U., Saad, T., \& Mollah, A. H. (2012). EPI Coverage among fewer than 5 children attending pediatric department of Dhaka medical college hospital. Faridpur Medical College Journal, 7(2), 59-62.

41. Siddiqui, N. S., Gaikwad, A. K., Kuril, B. M., Ankushe, R. T., Doibale, M. K., Pund, S. B., \& Kumar, P. (2017). Is mothers' knowledge and practice regarding childhood immunization 
compliant with immunization completeness? Int $J$ Community Med Public Health, 4(3), 775-80.

42. Adefolalu, O. A., Kanma-Okafor, O. J., \& Balogun, M. R. (2019). Maternal knowledge, attitude and compliance regarding immunization of under five children in Primary Health Care centres in Ikorodu Local Government Area, Lagos State. Journal of Clinical Sciences, 16(1), 7.

43. Owais, A., Hanif, B., Siddiqui, A. R., Agha, A., \& Zaidi, A. K. (2011). Does improving maternal knowledge of vaccines impact infant immunization rates? A community-based randomized-controlled trial in Karachi, Pakistan. BMC public health, 11(1), 239.

44. Wegwarth, O., Kurzenhäuser-Carstens, S., \& Gigerenzer, G. (2014). Overcoming the knowledge-behavior gap: the effect of evidence- based HPV vaccination leaflets on understanding, intention, and actual vaccination decision. Vaccine, 32(12), 1388-1393.

45. Gross, M., Tran, C., Sutherland, K., Castagno, J., \& Amdur, R. (2014). Pilot Study. Obstetrics \& Gynecology, 123, $114 \mathrm{~S}-115 \mathrm{~S}$ https://journals.lww.com/greenjournal/Abstract/20 14/05001/Pilot_Study__Can_an_Educational_Int ervention.234.aspx

46. Barrera, L., Trumbo, S., Bravo-Alcántara, P., Velandia-González, M., \& Danovaro-Holliday, M. (2014). From the parents' perspective: a usersatisfaction survey of immunization services in Guatemala. BMC Public Health, 14(1). Retrieved from:

https://www.ncbi.nlm.nih.gov/pubmed/24597643 